\title{
WHY DO COMPANIES FORTIFY? \\ DRIVERS OF COMPLIANCE WITH EDIBLE OIL FORTIFICATION IN BANGLADESH
}

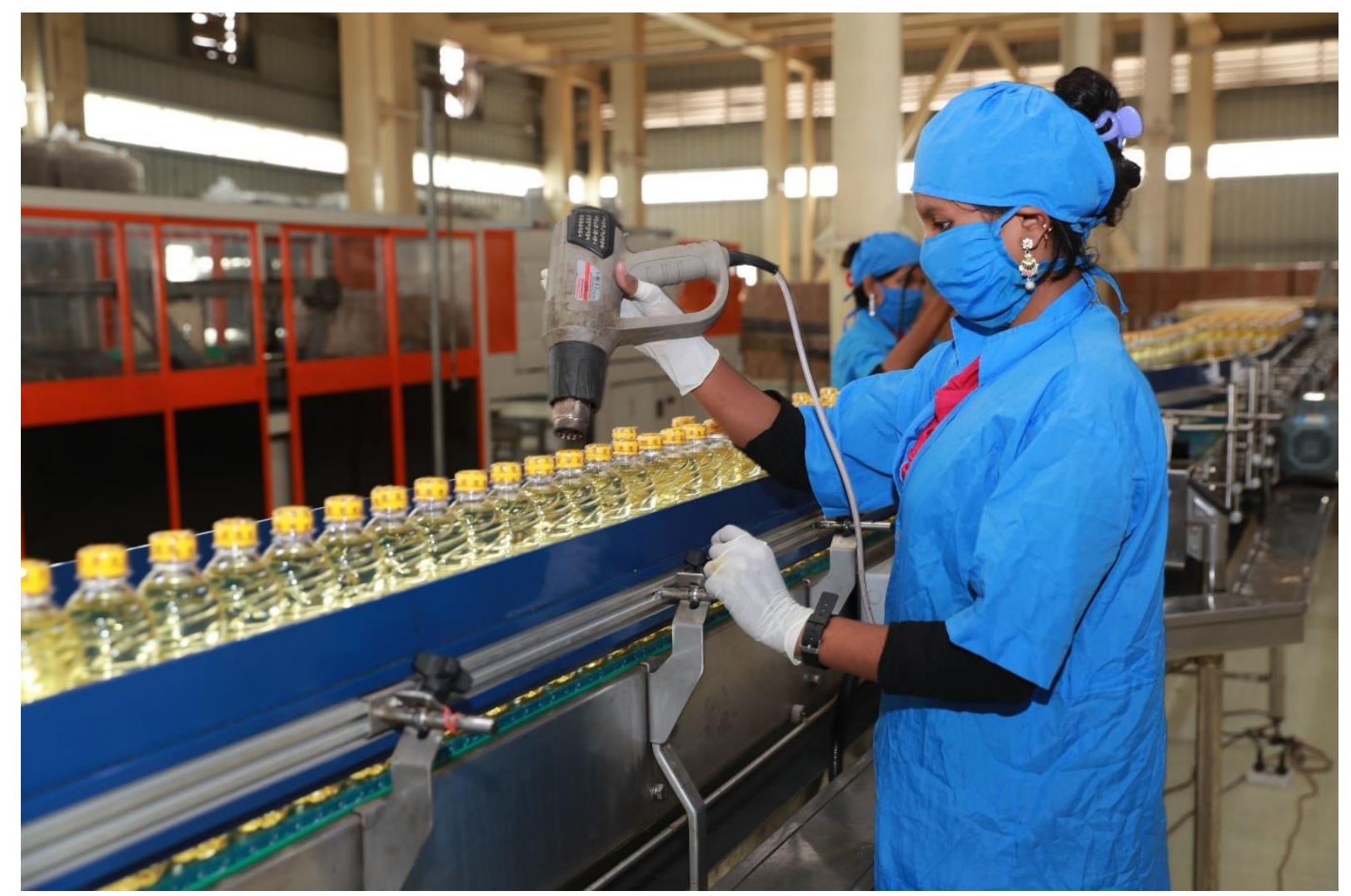

GAIN Working Paper n8

August, 2020

Mduduzi NN Mbuya, Jodie Thorpe, Abigail Carpio, Ainee Islam, Amrita Saha, Mysbah

Balagamwala, Sabiha Sultana, Rubaiyath Sarwar, and Ayako Ebata

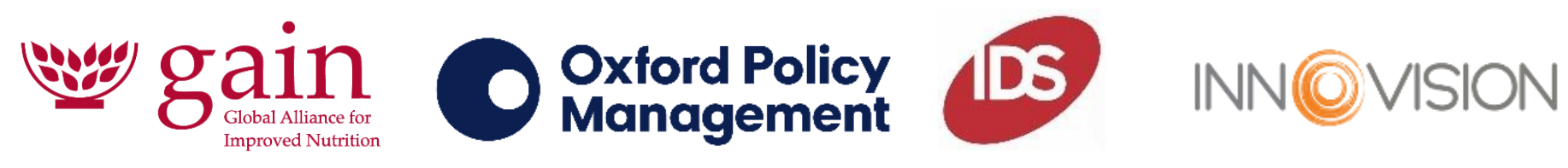




\section{ABOUT GAIN}

The Global Alliance for Improved Nutrition (GAIN) is a Swiss-based foundation launched at the UN in 2002 to tackle the human suffering caused by malnutrition. Working with governments, businesses and civil society, we aim to transform food systems so that they deliver more nutritious food for all people, especially the most vulnerable.

\section{Recommended citation}

Mbuya M.N.N, Thorpe J, Carpio A, Islam A, Saha A, Balagamwala M, Sultana, S., Sarwar R. and Ebata, A. Why do companies fortify? Drivers of compliance with edible oil fortification in Bangladesh. Global Alliance for Improved Nutrition (GAIN). Working Paper \#9. Geneva, Switzerland, 2020. DOI:

https://doi.org/10.36072/wp.8

\section{(C) The Global Alliance for Improved Nutrition (GAIN)}

This work is available under the Creative Commons Attribution-Non-Commercial-Share Alike 4.0 IGO licence (CC BY-NC-SA 4.0 IGO; https://creativecommons.org/licenses/by-nc-sa/4.0/). Under the terms of this licence, you may copy, redistribute, and adapt the work for non-commercial purposes, provided the work is appropriately cited, as indicated below. In any use of this work, there should be no suggestion that GAIN endorses any specific organisation, products or services. The use of the GAIN logo is not permitted. If you adapt the work, then you must license your work under the same or equivalent Creative Commons license. The contributions of third parties do not necessarily represent the view or opinion of GAIN.

\section{Acknowledgements}

We would like to thank the data collection team, Mar Maestre Morales (IDS) for her inputs to the study design, and gratefully acknowledge the contribution and insights of Rudaba Khondker, Atanu Chanda and Kazi Muinur Rahman from GAIN Bangladesh. The research could not have been accomplished without the support of the Ministry of Industries' (MOInd), especially Md Abdul Halim, Honourable Former Secretary MOInd, Dr Md Al Amin Sarker, Project Director, Fortification Edible Oil in Bangladesh Phase III and Deputy Chief, MOInd, and Ataur Rahman Siddiquee, Project Director, Control of lodine Deficiency Disorders (CIDD) and Director (Engineering \& Project Implementation), $\mathrm{BSCIC}, \mathrm{MOInd}$. We gratefully acknowledge the financial support of the Bill and Melinda Gates Foundation for this research project.

All photographs included in this document have been taken with consent for use in publications.

\section{GAIN WORKING PAPER SERIES}

The GAIN Working Paper Series provides informative updates on programme approaches, research and evaluations, and on topics of relevance for our work.

The Global Alliance for Improved Nutrition (GAIN)

Rue de Varembé 7

1201 Geneva

Switzerland

T: +41227491850

E: info@gainhealth.org

www.gainhealth.org

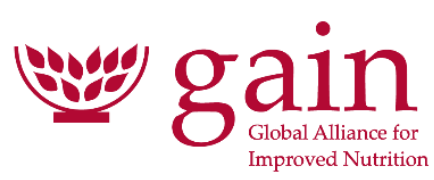




\section{SUMMARY}

This study responds to earlier findings of suboptimal compliance with mandatory fortification of edible oil in Bangladesh. We aim to explain the root causes of poor compliance and to provide recommendations to strengthen the national fortification programme in Bangladesh and other similar contexts.

We outline the structure, processes, and dynamics of both bulk and bottled edible oil value chains, and we analyse the factors that drive or impede compliance behaviour among edible oil producers. Our research shows that the cost of premix coupled with competition on price negatively affect profit margins for both oil refineries and oil packers. Along with inadequate regulation of the market, this has a negative impact on compliance, particularly in the case of bulk oil. In addition, access to quality vitamin A premix from accredited suppliers is a particular problem for smaller oil packers. On the other hand, producers that are subject to a higher-than-average frequency of inspections exhibit more behaviours associated with compliance. This finding is based on an innovative compliance behaviour score developed for and applied in this study.

We conclude with five recommendations to improve fortification outcomes: introduce appropriate labelling to ensure that bulk oil is traceable; implement producer inspections at least quarterly, with greater resources to support this effort; strengthen penalties for noncompliance, along with positive reputational incentives; ensure that suitable premix is available to all producers; and strengthen and improve data-driven monitoring of compliance. Further areas of research should include the development of new and more efficient/effective regulatory measures, such as digital solutions or systematic producer behaviour monitoring.

KEY MESSAGES

- Fortification programs are often constrained by sub-optimal compliance to national standards. This is the case for edible oil fortification in Bangladesh.

- Our study illustrates the value chain for edible oil and provides insights on the fortification process and drivers of compliance in Bangladesh.

- Higher frequency of producer inspections and knowledge among producer-level staff of fortification's benefits are associated with higher compliance.

- Stronger and more consistent penalties are important to ensure compliance, as well as acknowledging compliant and responsible producers.

- In addition, making quality premix available to all producers, ensuring traceability of bulk edible oil, verification of data on premix use and production levels provided by producers, and allocating resources for monitoring quality and safety are key. 


\section{BACKGROUND AND OBJECTIVE}

The fortification of staple foods and condiments with micronutrients has been shown to improve nutritional and functional outcomes and to do so cost effectively (1-3). However, sub-optimal implementation and delivery limit the potential for impact (4). In Bangladesh, the fortification of edible oil was initiated in response to widespread vitamin A deficiency; in 2011, one in five children of school age was estimated to be vitamin A deficient (5). Vitamin A deficiency is the leading cause of preventable blindness in children and is associated with greater risk of maternal and child mortality. As such, its mitigation is a public health imperative. Vitamin A supplementation programmes were already in effect but were estimated to be inadequate, as they only addressed the needs of children under 5 , not the whole population. However, a large proportion of Bangladesh's population, including across different sub-groups, was estimated-and subsequently confirmed-to have access to fortifiable (industrially processed) edible oil (6), suggesting that mandatory fortification of edible oil with vitamin A would be an effective complementary approach.

The law that made the fortification of edible oil with vitamin A mandatory in Bangladesh was enacted in November 2013 (7). It stipulated that all edible oils be fortified with vitamin A, including locally produced, refined, and imported products. There was initial resistance to the law from industry, represented by the Bangladesh Vegetable Oil Refiners \& Vanaspati Manufacturers Association (BVORA), which anticipated strong regulatory enforcement and quality-control mechanisms, and concomitant costs to compliance. Following a 14-month period of advocacy, legal argument, evidence generation, and stakeholder engagement (8), the "Oil Fortification Rules 2015" were published in the Bangladesh Gazette in November 2015 (9). The law is currently under review and an amendment is expected.

The law defines compliance with the fortification standards, articulates the rules for enforcement, and empowers the Bangladesh Standards and Testing Institution (BSTI) under the Ministry of Industries (MOInd) as the nodal agency for regulatory enforcement and monitoring. Effectively, the legislation mandates a fortification range of 15-30 mg retinol equivalents (RE) per kg according to the most recent national standards. Currently all $50^{1}$ edible soybean and palm oil ${ }^{2}$ producers registered in Bangladesh have signed memoranda of understanding with the MOlnd, to signal their commitment to fortifying edible oil with vitamin A. Producers include both oil refineries, which purchase and process oilseeds or crude oil and sell the refined oil in bulk and in bottles, and oil packers, which purchase bulk refined oil to bottle and sell.

International experiences have shown that while mandatory national fortification is important, it does not guarantee effective coverage of fortified foods (i.e., a sufficient proportion of people consuming the fortified food in amounts sufficient to provide the intended nutrients)

\footnotetext{
${ }^{1}$ We calculate that there are roughly 50 registered producers of edible soybean and palm oil (11-12 oil refineries and 38 oil packers). There are two issues with data on the number of producers. The first is that while many of them are legally registered, there are estimated to be over 50 unregistered oil packers. The second is that there is a distinction between the number of production sites and the number of business entities, given that the large producers own multiple sites.

${ }^{2}$ The types of edible oil that are the focus of this study are soybean oil and palm oil. These are the most widely consumed in Bangladesh and are considered fortifiable (on account of the process used to produce them). Along with rice bran oil, these are the edible oils that are legally required to be fortified with vitamin A. Rice bran oil is not widely consumed within the country and tends to be produced for export to other countries, so it is not included in this study.
} 
or the attainment of associated health benefits $(4,10)$. This is mainly because producers often lack sufficient incentives and capacities to conform with the legislation. This is borne out by the Bangladesh experience, where a market assessment of 553 retail outlets in the country's eight divisions was conducted by GAIN and icddr, b in $2017(11,12)$. The study was designed to ascertain the extent to which both branded edible oil and bulk (unbranded) oil conform with national fortification standards for vitamin A content. It found that only $59 \%$ of oil available in Bangladesh was fortified: in the case of bottled (i.e., branded) oil (which has a market share of $35 \%$ ), $95 \%$ was fortified (of which $69 \%$ was above the minimum standard). In contrast, for bulk oil (which has a market share of $65 \%$ ), just $41 \%$ was fortified (of which $7 \%$ was above the minimum standard).

In addition to these generally poor fortification programme performance outcomes, the lack of a labelling system and therefore the lack of traceability of bulk oil in Bangladesh means that there is no way to guarantee that a product is authentic, of good quality, fortified, and safe (13). The drums used to transport bulk oil are often repurposed and procured from unregulated sources-meaning that they are not necessarily food-grade containers.

Legislation, therefore, is clearly not enough to guarantee fortification compliance. International studies suggest that regulatory and economic drivers lie behind this suboptimal degree of compliance. First, regulatory monitoring is often lacking. This is driven by a lack of clarity in the structure and roles of government authorities, a lack of clarity in the legislation and regulations themselves, and limited financial and human resources to effectively monitor compliance $(14,15)$. Second, it is important to note that companies, like consumers, are susceptible to economic pressure. Often, edible oil is characterised by relatively inelastic market demand (i.e., demand that changes little in response to price changes). In addition, there are costs associated with fortifying correctly, including procurement and addition of premix - the powdery blend of vitamins and minerals used in fortification. Together, these factors create incentives for non-compliance. In survey responses across 17 countries, industry representatives indicated that the main barriers to ensuring adequate fortification were the high price of premix and competition from non-fortifying or non-compliant producers (14).

However, there is a paucity of examples in the literature to provide guidance on the best way to address such issues. More evidence-based recommendations are needed on how best to incentivise fortification compliance and how to deploy consistent consequences that will discourage non-compliance and drive under-fortified foods out of markets. To do so, it is important to understand the edible oil value chain, including how bulk oil sold in drums reaches the market, and to understand the factors underlying key decisions along the value chain, including those that influence differential producer compliance. Such information is needed to formulate corrective actions grounded in a clear theory of change.

In this paper, we report on the findings of a series of studies conducted to characterise the edible oil value chain in Bangladesh and to identify factors that can explain the differential outcomes (between bottled and bulk edible oil) and the suboptimal quality of fortification overall. Because the economic literature identifies various factors that influence company behaviour in the face of various constraints, including government regulation (16-18), we use 
it as our lens for analysing the results and informing the development and application of methods to explain the findings detailed above.

Based on this evidence, we present policy and programmatic recommendations for improving compliance of edible oil fortification through national programme standards. The overall goal of the paper is twofold. First, it offers information that will facilitate the development of a self-sustaining system that substantially improves edible oil fortification outcomes in Bangladesh. Second, it serves as a model for other countries to learn from and adapt findings to their own circumstances.

\section{METHODOLOGY}

In conducting this research, we used a theory-based and mixed-methods analysis to understand the market, value chain, and regulatory factors that influence edible oil producers' compliance with national fortification programme standards. The value chains that are the focus of this study involve bulk and bottled soybean oil, palm oil, and super-palm oil ${ }^{3}$, as these are the most widely consumed fortifiable edible oils in Bangladesh.

We sought to answer three research questions, with each question organised as a distinct sub-study. ${ }^{4}$ These are listed below. Across all three components, we maintain confidentiality of study participants, presenting aggregate-level information only.

Question 1. What is the nature of the edible oil value chains, including the origination, distribution, and transportation of bottled and bulk products? (19) We used value chain analysis to identify and map the actors involved in the production, distribution, and sale of edible oil, assessing their role in the production and delivery of fortified oil and establishing how the relationships between different actors and activities influence these processes. The analysis also highlights constraints, challenges, and opportunities for reform to make fortified edible oil available and accessible to consumers.

Data collection involved gathering and reviewing relevant secondary data, including industry data sourced from the MOlnd and market studies on the edible oil sector, as well as policies, laws, and regulations related to the edible oil sector. Semi-structured interviews were carried out with four oil refineries and six oil packers, primarily with owners or general managers of these businesses. Oil refineries were purposively selected from a list provided by the Molnd while oil packers were selected in consultation with the Bangladesh Edible Oil Packaging Association (BEOPA) and through a snowballing sampling method that identified additional packers. Interviews were also carried out with other value chain actors (such as input providers and retailers), development partners, relevant government agencies (notably the $\mathrm{BSTI})$, and BEOPA.

Question 2. What factors underlie decisions along these value chains and affect food fortification outcomes? (20) We employed qualitative methods to collect data on economic

\footnotetext{
${ }^{3}$ In some cases, producers of edible oil also offer 'Super Palm Oil', which can be described as a better form of palm oil; it can withstand colder temperatures than (regular) palm oil.

${ }^{4}$ Although each sub-study was designed separately, the data collection was integrated in specific instances where this would minimise stakeholder fatigue. In particular, data collection was integrated for some of the semi-structured key informant interviews related to the first two (value chain) questions.
} 
and regulatory factors driving the behaviour of value chain actors, as well as on consumer perspectives. These involved semi-structured interviews with value chain actors as well as with stakeholders outside the value chains who have relevant knowledge regarding the factors affecting fortification decisions. In addition, we carried out a series of focus group discussions with edible oil consumers.

Stratified purposeful sampling was used to identify value chain actors for interview. We aimed to select those considered 'typical' of their position in the value chain, while also seeking variation, particularly in terms of size (e.g., in relation to producers) and geography (e.g., in relation to retailers and consumers). In total, 26 semi-structured interviews were conducted with oil refineries, oil packers, wholesalers, retailers, and premix providers, primarily with the owners or general managers of these businesses. Five key informant interviews with government agencies and development partners also took place. Five focus group discussions were conducted with low- and middle- income consumers, involving 37 participants. Interviews and focus group discussions were conducted in Natore, Rangpur, Narayanganj, Dhaka, Gazipur, Chattogram, and Sylhet districts, in order to understand different contexts across Bangladesh.

Question 3: How is producer (oil refinery and oil packer) behaviour influenced by market and regulatory constraints? (21) We designed and implemented a producer-level survey with 35 oil producers (both oil refineries and oil packers) to allow us to capture the producers' behaviour in relation to compliance, including details of how oil producers understand and respond to relevant regulations. To capture compliance, we generated a compliance behaviour score. This innovative metric measures underlying aspects of compliance based on access to and use, source, and quality of the process and equipment for fortification. This score comprises seven components: storage facility for premix; premix measurement equipment; mixers; titration equipment; blenders; fortification-related IT use; testing samples (single 'grab sample'; composite sample); and recording of premix, mixing, and final products.

We then compared the 'complying' and 'non-complying' producers based on these calculated compliance behaviour scores, in order to identify and model the drivers of compliance. We used the econometric analysis technique of multiple regression to examine the significant factors that explain producers' compliance with food fortification regulation and to predict the likelihood of compliance behaviour associated with changes in these drivers. Additionally, we used formal robustness checks to examine the structural validity and robustness of the results.

By integrating the findings across these three studies, this paper explains in depth the structure and dynamics of the edible oil value chain and offers cross-cutting analysis that integrates quantitative and qualitative insights. It offers a detailed understanding of company-level (rather than consumer-level) behaviour and incentives and uses this to generate policy recommendations to shape these incentives and influence producer behaviour towards compliance. In addition, the compliance behaviours index constructed for question 3 adds to the methods and metrics available for measuring fortification, offering a more rapid and less invasive approach than quantifying micronutrient content in food samples (22), although further application and validation are needed. 


\section{FINDINGS}

In this section we identify and map the actors involved in the production, distribution, and sale of edible oil (Figure 1). We then explain key processes in the value chain in more detail and finally show how the dynamics of the relationships between actors and activities, alongside regulatory factors, influence fortification outcomes.

\section{THE EDIBLE OIL VALUE CHAIN}

The main value chain actors in the production of edible oil in Bangladesh are oil refineries and oil packers. Oil refineries import crude oil from international exporters and produce both bulk and bottled oil, although there are no reliable data to show the extent to which individual oil refineries produce bottled versus bulk oil. Oil packers, on the other hand, are not involved in oil refining; they purchase edible oil in bulk from the refineries, which they filter and fortify with (additional) vitamin A if necessary to meet regulatory standards, and then package for sale to consumers. Oil refineries are larger and longer established. From our survey, oil refineries averaged 485 employees and had been operating for 22 years, while oil packers averaged 19 employees and had been operating for 9 years.

Distribution of bulk oil from the refineries is primarily through a 'delivery order (DO)' system. Both oil packers and wholesalers purchase bulk oil through DO dealers. These dealers send empty drums to refineries, with a DO to source the oil, which is then delivered to packers or to national or regional wholesalers. Wholesalers sell bulk oil to various retailers, hotels, and restaurants, as well as to the food manufacturing industry. Local wholesalers purchase oil drums from regional wholesalers and supply to village-level small-scale retailers.

For bottled oil, refineries and packers distribute their products to retailers either directly through their own sales representatives or through regional and local wholesalers, which stock bottled oil from different brands.

Consumers purchase bottled or bulk oil directly through village markets, small shops, and supermarkets, and also consume oil from other sources, such as bakeries and restaurants. 


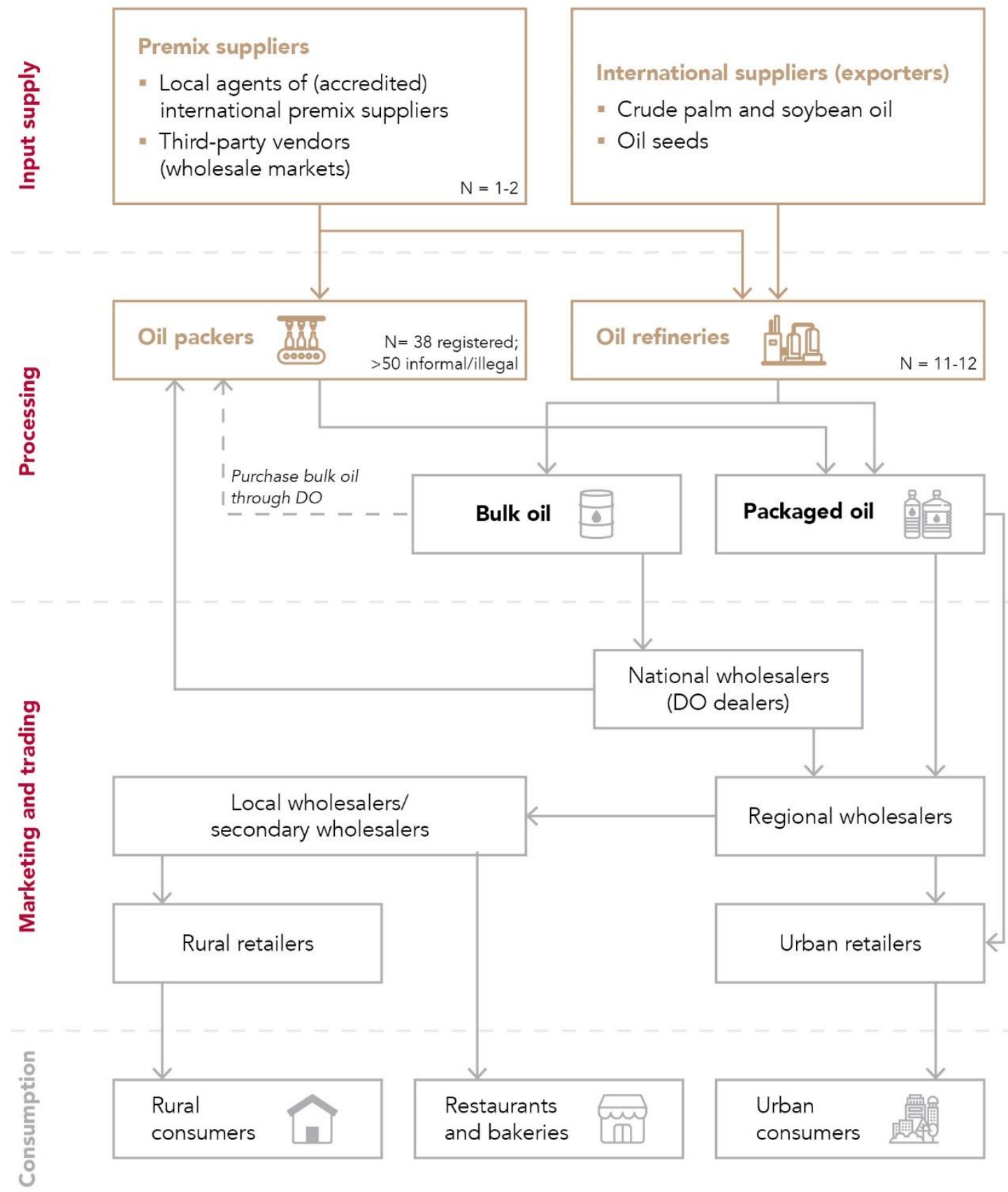

N-Number of actors; DO - Delivery Order

Figure 1: Edible oil value chain in Bangladesh 


\section{Products offered: bottled vs bulk oil}

Soybean and palm oil are the varieties of edible oil that are most widely used by consumers in Bangladesh. ${ }^{5}$ Refined soybean and palm oil are sold in both bottled and bulk form.

- $\quad$ Bottled oil is mostly packaged in plastic PET (polyethylene terephthalate) bottles, with branding of the respective oil refinery or oil packer. Sizes range from as little as 250 millilitres up to 16 litres. Bottled oil represents approximately $35 \%$ of the edible oil traded in the market.

- $\quad$ Bulk edible oil-also referred to as 'loose oil', especially at the retail levelrepresents about $65 \%$ of the edible oil traded in the market. It is produced by oil refineries only and is typically distributed in drums weighing $185 \mathrm{~kg}$.

Both bottled and bulk oil are available across Bangladesh, including in both rural and urban low- and middle-income areas. While retail chains and supermarkets in wealthier urban areas mostly carry bottled oil only, among consumers in low- and middle-income communities in rural and urban areas there is high demand for bulk oil. This preference appears to be driven by the difference in the price between bottled oil and bulk oil. Our research with retailers and consumers found that bottled oil was often BDT 15-20 (USD 0.17-0.23) per litre more expensive.

BEOPA estimates that around $15-20 \%$ of the edible oil that is traded comes from oil packers-and this is largely distributed and sold outside the main urban areas. Oil packers are better positioned to reach rural and peri-urban areas that are otherwise difficult for oil refineries to reach. However, oil refineries are trying to advance into these markets, thereby increasing competition in places where competition among oil packers is already intense.

As noted in the introduction, bottled oil is considerably more likely to be fortified than bulk oil ; with $95 \%$ of the market volume of bottled oil estimated to be fortified, compared with only $41 \%$ of bulk oil. Fortification according to minimum standards is lower for both types (69\% for bottled oil and 7\% for bulk oil).

\section{VALUE CHAIN PROCESSES}

\section{Role of oil refineries versus oil packers}

Oil refineries and oil packers differ not just in terms of the age, size, or scale of their operations but also in their very different business models.

Oil refineries differ from oil packers in that they have the capacity to refine crude or unrefined oil. Some oil refineries_e.g., those that produce soybean oil-process oilseeds, which are crushed or pressed to extract the oil. In each case, a refining process then follows. This broadly involves the removal of fatty acids, neutralisation, and repeated filtering, all the way through to bleaching and deodorising. These are capital-intensive operations. This processing capacity therefore requires a large, more complex organisation, equipped with machinery and a relatively large workforce.

\footnotetext{
${ }^{5}$ In some cases, producers of edible oil also offer 'Super Palm Oil', which can be described as a better form of palm oil; it can withstand colder temperatures than (regular) palm oil.
} 
Oil packers, on the other hand, are not smaller versions of oil refineries. They procure already processed or semi-processed oil from oil refineries, directly or indirectly, which they then pack and sell to consumers. Oil packers purchase edible oil in bulk from oil refineries- i.e., they do not import unrefined or crude oil, as they do not have refining capacity. The oil that they procure from refineries is essentially ready to be packaged and distributed. However, in practice, the oil that packers purchase goes through one more filtering process. This is mainly to remove dust or other foreign particles that may have become mixed with the oil in the course of being transported (from the refinery to the wholesaler to the oil packer). Otherwise, the functions of oil packers in the value chain are centred on packaging and distributing the oil.

The process of fortifying edible oil with vitamin A takes place at the oil refineries before edible oil is packaged for distribution. Using an automated system, the required dose of vitamin $A$ is added to the refined oil. After mixing, some of the fortified oil is sent to the bottling line. The rest is sent via a separate line to be held for collection through the DO system. When refineries receive a DO and drums, the oil will be poured into the drums for transport as bulk oil.

The oil that packers purchase from the refineries should, therefore, already be fortified. However, some oil packers have reported cases where the bulk oil they purchased was either not fortified at all or the vitamin A content fell below the legal requirement. In such instances, they are expected to fortify the oil before packaging it.

As the law currently holds both oil refineries and oil packers accountable for fortification, both require equipment to blend or mix the vitamin A premix with their batches of refined edible oil. Moreover, both oil refineries and oil packers must be able to access laboratory facilities as part of their quality assurance - to quantify the vitamin A in the oil they produce and trade, in order to ensure or confirm compliance. While most oil refineries maintain their own dedicated laboratory chemists, oil packers typically secure the services of a chemist who is not fully employed by the company. For example, they may contract a laboratory chemist who also works for other oil packers. The laboratory chemist is often also involved in the purchase of premix by oil packers-not least giving recommendations on how much and which brand to buy.

\section{Supply of premix}

Both oil refineries and oil packers routinely procure vitamin A premix. International suppliers such as BASF and Hexagon Nutrition (both based in India) sell premix in Bangladesh through local dealers or agents. ${ }^{6}$ While oil refineries tend to purchase the vitamin A premix directly from local agents of international suppliers, oil packers purchase it from third-party vendors in wholesale markets. This difference between oil refineries and oil packers is significant, since third-party vendors have been reported to sell low-quality premix, which may contribute to under-fortification.

\footnotetext{
${ }^{6}$ Around $80 \%$ of BASF's total sales of premix are direct sales made to oil refineries. When smaller volumes of the premix (e.g., $10-20 \mathrm{~kg}$ ) are required, this is sold through an agent.
} 
The difference in the purchasing practices of oil refineries and oil packers is partly explained by the difference in price offered by the different suppliers. Premix supplied by accredited companies sells for BDT 15,000 (approximately USD 173) per kg. Premix from other (nonaccredited) companies, which are supplied by third-party vendors, is significantly cheaper, at BDT 6,000 (USD 69) per $\mathrm{kg}$. The stabiliser contained in this variety of premix is reported to be inadequate, however, compared to the more expensive variety. ${ }^{7}$ The difference between the purchasing practices of oil refineries and oil packers is also influenced by the volumes they purchase. Local agents of accredited international suppliers stipulate a minimum purchase volume of premix - which is difficult for smaller operators (such as oil packers) to meet, especially in the absence of an effective mechanism to aggregate the demand for premix.

\section{Packaging and labelling}

The edible oil value chain in Bangladesh is fragmented, with poor coordination particularly in information sharing. Bulk oil, in particular, is transported and traded without adequate labelling, making it difficult, if not impossible, for retailers and consumers to distinguish between oil types. For example, there are suspicions that oil refineries, wholesalers, and/or retailers mislabel palm oil as soybean oil. ${ }^{8}$ Similarly, little reliable information on fortification status is shared across the value chain. Most value chain actors say that all products (bulk and bottled oil) are labelled as fortified and that they accept that the products they receive are fortified 'to some extent.'

There are also issues with the sourcing and management of the drums used for edible oil distribution. Wholesalers purchase or rent the drums from small businesses that collect and recycle used drums. The drums may not be made from food-grade materials and may be procured from chemical companies. It is difficult to tell whether these drums have been sterilised or cleaned well enough to be used for edible products such as oil.

In addition, many of the drums observed in the retail and wholesale markets were visibly dirty. The lids or the surfaces around the opening of these drums had dirt, dust, or other elements on them. When the drum is opened, it is reasonable to assume that the oil within it would be contaminated with these foreign elements. In some local markets, oil is transferred from these large drums to smaller containers for the purposes of retail, which increases the risk of contamination.

\section{Role of the government in monitoring and enforcement}

The Bangladesh Standards and Testing Institution (BSTI) is the regulatory authority for the edible oil sector within the MOlnd and carries out monitoring and enforcement of oil fortification laws. Initially, the MOInd focused on the refineries, as the primary producers of edible oil. Successful enforcement of fortification requirements at this level would have ensured

\footnotetext{
${ }^{7}$ Grade B vitamin A premix imported from China was reported to be available in the market. According to one interviewee, Grade B premix does not have 'Tocoferol Antioxidant' (which is included in higher-quality premix). It is therefore volatile to sunlight exposure, leading to risk of faster degradation of vitamin A, although we were not able to independently verify this. Such premixes are mainly sold at the chemical wholesale market of Mitford, Dhaka.

${ }^{8}$ Soybean oil is more expensive and is generally considered by consumers to be superior to palm oil.

${ }^{9}$ These drums are very similar (even identical) to the packaging used for other chemical products or non-food items (e.g., paint). Some chemical companies reportedly contact wholesalers whenever they want to dispose of drums.
} 
that all oil in Bangladesh was adequately fortified. ${ }^{10}$ However, inadequate results led to oil packers also being included in monitoring and enforcement. Both oil refineries and oil packers have to apply to BSTI for a license to produce (fortified) foods and show that they meet national food standards and other requirements. BSTI conducts inspections of both refineries and packers. Inspections are expected to take place twice a year, once at production level and once at retail level. In our survey, most producers reported 1-2 inspections per year, although some reported no inspections, while others reported as many as 12 inspections per year. The average was 2.6 inspections per year.

At the production level, inspections review elements such as the conditions of premises and equipment, the capability of personnel, internal quality control measures and equipment, and product samples. At the retail and market level, BSTI collects samples of bottled edible oil and tests fortification quality. However, the bulk oil produced by refineries cannot be inspected at retail level ${ }^{11}$ due to the lack of traceability. Despite the fact that BSTI has directed oil producers to follow the 'Package Commodity Rules 2007' by labelling drums with the name of the refining company and other details (20), inadequate labelling means there is no way to trace products back to oil refineries or to hold them accountable for under-fortified bulk oil. The government has proposed amending the law to ensure that only food-grade containers with proper labelling are used for transporting bulk oil, to ensure that it is traceable from its production site, but this change has not yet been approved.

Where producers are found to be in violation of the regulation, they are issued a warning and asked to submit a letter explaining why they failed to meet the standard in that instance.

They are expected to carry out corrective actions, and if not, their license can be cancelled by BSTI. $^{12}$ A mobile court run by BSTI also actively fines non-compliant edible oil producers.

Mobile courts are frontline institutions of the BSTI that conduct spot checks, apprehend the offender 'red handed,' examine witnesses, hear the accused, complete procedural requirements, and issue the mandated penalty instantaneously (23). At the time of data collection, BSTI appeared to be increasing its efforts to address the issue of non-traceable bulk oil; in June 2019, they confiscated four trucks containing bulk oil that were suspected of being unfortified (24).

In addition to inspections, producers are expected to share monthly data on the quantity of edible oil produced, premix purchased, and premix in stock, although there is no process in place for verifying this data. Moreover, our findings suggest producers are reluctant to accurately report production volumes. In our survey, all companies reported producing close to $95 \%$ branded products. However, the market share of branded products is in fact only $35 \%$, by volume (11). This low reporting of bulk oil production is presumably due to the high incidence of inadequately fortified bulk oil.

\footnotetext{
${ }^{10}$ Except for any vitamin $\mathrm{A}$ lost in transport and storage.

${ }^{11}$ Bulk oil is reported to be tested at the market level; however, where under-fortification is detected, the only measure open to the MOInd is to notify all refineries of the non-conformance. They cannot identify or penalise individual producers.

${ }^{12}$ It should be noted, however, that oil refineries and oil packers whose licenses are revoked or cancelled by BSTI may later reopen or reinstate operations, provided they meet a number of requirements.
} 


\section{DRIVERS OF INDUSTRY BEHAVIOUR}

In this section we identify the value chain dynamics and regulatory factors driving the behaviour of oil producers in complying with national programme standards for edible oil fortification in Bangladesh. Here we start from the downstream end of the value chain; in other words, with an exploration of consumer demand as it affects supply (production) in value chains. We then look at cost and regulatory factors.

\section{Demand side: Consumer purchasing decisions}

Consumers across geographies and income groups generally report that price is an important consideration in purchasing decisions. For example, although consumers describe soybean oil as being better for cooking purposes, they often choose palm oil due to its lower price (Table 1). In general, different consumer groups express a preference for bulk oil because of its lower price, except for special occasions such as weddings and Eid, when bottled oil is preferred. In terms of bottled oil, consumers are not 'brand-conscious' and do not report any significant difference in quality or price between brands or between oil refineries and oil packers.

Table 1. Oil prices paid by consumers across study sites (BDT per litre)

\begin{tabular}{|c|c|c|c|c|c|}
\hline \multirow{2}{*}{ Location } & \multirow{2}{*}{$\begin{array}{c}\text { Consumer } \\
\text { characteristics }\end{array}$} & \multirow{2}{*}{$\begin{array}{c}\text { Bottled } \\
\text { Soybean }\end{array}$} & \multicolumn{3}{|c|}{ Loose } \\
\hline & & & Soybean & Super palm & Palm \\
\hline Muhammadpur & Middle-income & $95-102$ & 90 & 85 & NA \\
\hline Natore & $\begin{array}{c}\text { Rural } \\
\text { Low-income }\end{array}$ & $95-105$ & 85 & 65 & 60 \\
\hline $\begin{array}{c}\text { Chattogram } \\
\text { environs }\end{array}$ & $\begin{array}{c}\text { Rural } \\
\text { Middle-income }\end{array}$ & $88-110$ & $N A^{\star}$ & $N A^{*}$ & $N A^{*}$ \\
\hline $\begin{array}{c}\text { Chattogram } \\
\text { environs }\end{array}$ & $\begin{array}{c}\text { Rural } \\
\text { Low-income }\end{array}$ & $88-110$ & $85-90$ & $85-90$ & $85-90$ \\
\hline Rangpur & Middle-income & 95-105 & $83-85$ & 65 & NA \\
\hline
\end{tabular}

*Consumers in the middle-income focus group discussion in Chattogram said they did not purchase loose oil Source: Authors' analysis, based on price reported by consumers during focus group discussions

Urban middle-income households consume both bottled and bulk oil. Although some upper middle-class households buy bottled oil for regular consumption because of its convenience, most middle-income families reported buying bulk oil for daily consumption and bottled oil for festive occasions. In rural areas, consumers buy bulk oil from the retail shops closest to them or from the village market during Haat (market) days. They reported acquiring 2-3 litres of oil per month on average, although households that earn daily wages buy bulk oil in smaller amounts (250-500 millilitres). Urban low-income consumers also buy bulk oil regularly.

Consumer awareness of fortification in oil is low across all strata. Consumers told us that they were not concerned about vitamin A fortification. Participants also reported a lack of trust in product claims; in particular, they believed that oil sold as 'soybean' is sometimes really palm oil. Retailers also claimed that the oil they purchased from wholesalers or distributors was sometimes mislabelled. 
Overall, our findings suggest that consumers generally prefer bulk oil due to price, but that it is not always a basic issue of affordability. Instead, consumers across income strata weigh the relative cost and perceived value of available options, and many judge that the added benefits of bottled oil are not sufficient to warrant paying the higher price on a regular basis.

\section{Supply side: The added cost of fortifying}

The main cost of fortification for producers is the premix, which is sold at BDT 15,000 per kg (approximately USD 173), or BDT 0.75 to 0.85 per litre of oil. In absolute terms, this is a small percentage of the total cost of production. However, when calculated as a percentage of net profit, this cost becomes more substantial, particularly for bulk oil. Although we were unable to retrieve precise cost and profit figures directly from the producers, we estimated oil producers' profits based on interviews with industry informants (Table 2). Based on these figures, we calculate that if oil refineries do not fortify, they can earn 34-38\% additional operating profit per litre of bottled oil, while for oil packers the figure rises to $43-50 \%$. However, the impact is greatest for bulk oil, where oil refineries can earn 57-75\% further operating profit. While these figures should be taken with some caution, they do highlight the relatively higher benefits of under-fortifying bulk oil.

Table 2: Cost, revenue, and profit for oil refineries and oil packers (BDT per litre)

\begin{tabular}{|c|c|c|c|}
\hline \multirow{2}{*}{ Details } & \multicolumn{2}{|c|}{ Oil Refineries } & Oil Packers \\
\hline & Bottled oil & Bulk Oil & Bottled oil \\
\hline Revenue per litre of oil & BDT 90 & BDT 75 & BDT 85 \\
\hline Gross profit* & BDT 6 to 7 & BDT 5 to 6 & BDT 4 to 5 \\
\hline Operating (net) profit** & BDT 2 to 2.5 & BDT 1 to 1.5 & BDT 1.5 to 2 \\
\hline Operating profit for non-fortified oil & BDT 2.75 to 3.35 & BDT 1.75 to 2.35 & BDT 2.25 to 2.85 \\
\hline Additional profit for non-fortified oil & $34-38 \%$ & $57-75 \%$ & $43-50 \%$ \\
\hline
\end{tabular}

*Revenue minus cost of producing fortified oil; ** Gross profit minus administrative costs and other costs involved in the operational process for producing fortified oil

Source: Authors' own, based on information reported by industry informants

In order to maintain profit levels, companies would need to either increase revenues or find cost efficiencies elsewhere in production. As described above, fortification is unlikely to raise demand, thus limiting its potential to increase revenues. That said, there is some demandside incentive if under-fortification compromises company brands and reputation. However, this dynamic is only relevant for bottled oil, as bulk oil cannot currently be traced to the producer.

In terms of cost efficiencies, large oil refineries may be able to offset some of the cost of fortifying bottled oil through production and scale efficiencies across refining, packaging, and distribution activities. For bulk oil, there are fewer opportunities for such efficiencies, as there are no packaging or distribution activities.

For oil packers, there is limited scope for cost efficiencies, as they are not involved in refining, and their business model is already based on low prices. According to BEOPA, it is the already low overhead costs of oil packers (relative to oil refineries) that enable them to offer retailers edible oil products that are slightly cheaper than those offered by the oil refineries. 
Oil packers also cited further downward pressure on already thin profit margins due to intense competition among oil packers and particularly from oil refineries, which are trying to advance into new, more remote markets.

The net effect of these dynamics is that despite the apparently low cost of premix, there is a clear incentive for oil refineries to under-fortify bulk oil. If oil packers then purchase bulk oil that has not been adequately fortified, the reputational incentives to fortify have to be weighed against competitive pressures to minimise costs. In addition, where oil packers do add premix, they are likely to choose cheaper premix, particularly if they lack sufficient information and know-how to judge the quality of different premix sources.

\section{Regulatory drivers: Fines and other enforcement measures}

For those who violate the fortification law, fines range from BDT 50,000 (USD 575) for the first offence to BDT 200,000 (USD 2,300) for subsequent offences, which may be accompanied by imprisonment for terms ranging from six months to five years (7). One key government official we spoke to, however, expressed the view that the fine for noncompliance is too low for the large refineries, as it is not significant compared to the size of their business. Beyond fines, regulators can 'name and shame' producers that fail to meet legal fortification requirements, and this reputational damage can itself be a serious consequence of non-compliance.

The issue, however, as can be observed from the value chain processes described above, is that both of these 'sticks' (fines or 'naming and shaming') are only applicable to bottled oil. Unless the lack of traceability of bulk products can be addressed, inspection and enforcement at the production level is the only regulatory driver for adequate enforcement. ${ }^{13}$

Interestingly, our survey found that producers that scored higher on the awareness index ${ }^{14}$ were more likely to follow fortification regulations. All other factors being kept equal, an increase of one point in the awareness/knowledge score increased the likelihood of compliance by 31 percentage points. This suggests that there is value in investing in education and awareness on fortification at the producer level when promoting compliance.

In addition, the survey found that those producers that are inspected more frequently actually perceive the costs of fortification to be lower than those that are inspected less often. This may be partly due to the recent introduction and implementation of the fortification regulation by MOInd and BSTI. At this early stage, more persistent regulatory audits may have particular value in ensuring that oil producers become accustomed to the necessary requirements for effective compliance and see them as less burdensome.

\section{DISCUSSION: KEY ISSUES AND OPPORTUNITIES FOR POLICY}

In this paper, we have presented in detail the value chains for edible oil in Bangladesh from source, through processing companies, to consumers. We have also described the processes that underlie fortification and regulation of the national fortification mandate. This study was

\footnotetext{
${ }^{13}$ After this research was completed, there was reportedly a case in which BSTI inspected trucks loaded with bulk oil shortly after they had left the refinery. Inspectors were able to use the DO that accompanied the drums to trace the oil back to the refinery that produced it.

${ }^{14}$ This measured producer awareness of regulatory developments, the level of consumption of fortified oil, the consequences of vitamin A deficiency, and the implications of transportation, storage, and distribution for fortificant levels.
} 
primarily designed to respond to earlier findings of suboptimal compliance in Bangladesh, particularly with respect to fortification of bulk edible oil, and to provide explanatory as well as corrective insights. Its findings will also strengthen the national fortification programme in Bangladesh and similar contexts. Several issues are therefore worthy of further discussion and emphasis.

\section{DESIRABILITY OF MANDATORY FORTIFICATION IN THE BANGLADESH CONTEXT}

The logic of having a mandatory national fortification programme is to ensure a passive delivery of nutrients, with no behaviour change needed on the part of the consumer to obtain the benefits. This programme logic is sound in Bangladesh. One basis for this assertion is the evidence of need as represented by the prevalence of vitamin A deficiency in the Bangladeshi population (as earlier discussed) and the coverage of fortifiable oil among those with potential to benefit (6). Another consideration is in the low level of awareness of the health benefits of vitamin $A$, as well as the fact that consumers are unable to verify the level of vitamin $A$ in fortified oil (i.e., vitamin $A$ in oil is a 'credence good,' which consumers must trust exists) (25). Because there is no way for consumers to observe fortification quality, they must rely on the seller's credentials, so supply-side intervention is key. However, ensuring that all the oil (especially bulk oil) that reaches consumers is adequately fortified remains a challenge, especially given the lack of demand-side factors that would incentivise producer compliance.

\section{WEAK AND CONFLICTING INCENTIVES DISCOURAGE FORTIFICATION}

Our research revealed weak and sometimes conflicting incentives that discourage fortification. For consumers, these include the prices they are willing to pay and perceptions of quality, as determined by colour and oil type. For producers, they include brand reputation and the perceived ineffectiveness of fines. These will need to be realigned to ensure the delivery of much-needed nutrients. For consumers, we can surmise that the relative cost and perceived value of available edible oil options drive purchasing decisions towards bulk oil, as the more affordable alternative. This is a more nuanced proposition than the conventional perception of consumers being only or largely price sensitive, or the notion that awareness is the most important binding constraint. Our findings can be interpreted in the context of the observation (26) that brand credibility can reduce price sensitivity. Demand-side interventions should focus on the perceived value of bottled oil. Encouraging the consumption of bottled oil, which is more likely to be fortified, can be effective, and characteristics that consumers say they value, such as cleanliness and freshness, can be emphasised. Better yet, per the implicit programme theory of fortification, efforts can focus on obviating consumer choice by driving unfortified products out of the market.

For companies, our observations challenge the conventional assumption that the costs of fortification are low. It has been estimated that the cost increase resulting from fortifying oils with vitamin A amounts to only $0.1 \%-0.3 \%$ of the retail price (27). By focusing our analysis on the impact on profits, however, we estimated that not fortifying may generate between $34 \%$ and $75 \%$ of additional operating profit per litre of oil. Importantly, the greatest profits are realised by distributing bulk oil that is not fortified. Clearly there is an incentive to underfortify, as well as to bifurcate supply chains to deliver under-fortified bulk oil. It is important to 
note that MOlnd has taken the decision to amend the existing law to address these issues and gradually remove drums as the bulk oil container. However, we posit that the effects of price competition and the costs of fortification in an under-regulated market negatively affect company compliance, and effect oil refineries and packers differently. Survey responses (14) and miller reports (22) from international research have underscored the fact that companies face competition from unfortified (noncompliant) products as long as these remain in the marketplace.

Furthermore, strengthening regulatory monitoring and enforcement of the law is critical. BSTI inspections at production sites and retail outlets are the primary means through which noncompliance is identified and consequent penalties issued. However, given the market assessment findings that a significant proportion of bulk oil is unfortified or under-fortified, we must conclude that these inspections are inadequate, particularly with respect to bulk oil (8). Additionally, we identified more oil packers than were initially assumed, as many are informal or unregistered. It is possible that, on the one hand, packers avoid registration in order to avoid taxation and/or regulatory monitoring, or, on the other hand, that the government system is not adequately equipped to fully register packers. This poses a challenge for effective monitoring across the value chain. We posit that accountability for fortification resides primarily with refineries as the main producers responsible for fortifying oil. Some accountability, albeit secondary, also lies with packers, to ensure they purchase fortified oil and top up the pre-mix as necessary. Appropriate enforcement alongside effective penalties is required to ensure a deterrent effect, and this requires a focus on whom to hold accountable.

Stronger and more effective regulatory monitoring needs to be coupled with consistent and effective incentives for companies. Greater frequency of inspections is needed, given their strong association with compliance in our data, which indicate that inspections at the producer level are associated with higher compliance. Clearly, appropriate resources need to be allocated to monitoring and surveillance.

Based on the study findings, we also posit that awareness and knowledge transfer should be directed towards producers, given the strong and robust relationship identified between awareness — of both the regulation and the health benefits of fortified oil-and the compliance behaviour index. This would represent a paradigm shift, as awareness and behaviour change interventions have traditionally been targeted at consumers. There is some discussion in the literature of the value in viewing inspections and the regulatory process as more than just the means to deliver a stick (penalty) but as an opportunity for interaction between public- and private-sector actors $(28,29)$. Specifically, regular dealings, information exchange, and a motivational element to interactions between inspectors and producers (e.g., a focus on negotiating cooperation and preventive aspects, and not just compliance/non-compliance) can enhance cooperation, reduce information disparities, and strengthen regulatory cultures. This might be a channel through which producer awareness and knowledge of fortification and its implications, which we determined to be a significant correlate of fortification, can be improved. At the same time, producer confidence in the regulatory process and the effectiveness of penalties can also be improved. 
The Government of Bangladesh has committed to eliminating drums for transporting and storing bulk oil. In addition, BSTI is increasing the frequency and enforcement of its surveillance. This has been reflected in press releases since our research took place. These have appeared every month from March to May 2020,15 exposing products being banned and naming producers (or acknowledging unbranded, untraceable products). We commend these steps and suggest that this is a necessary measure that needs to be maintained. Some of the increase in the frequency of inspections is due in part to financial support from development partners. For sustainability, government allocations will also be needed.

Access to good quality vitamin A premix-a key input for fortification-is another area where constraints have been identified. Small and medium-sized oil producers-such as oil packers-access premix supplies that are of poor quality. The problem appears to be driven by limited information (as communicated to oil packers) about specific premix products and suppliers; the absence of clear regulations (and their enforcement) and guidelines on what constitutes the 'right premix' and where to source it; and the inability of oil packers to procure from agents of accredited international suppliers, given the disparity between how much volume oil packers need and the minimum volumes these agents sell. MOInd and GAIN are currently working with local businesses to explore the potential relevance, feasibility, and business viability of establishing an accredited intermediary warehouse in Bangladesh. This would aggregate demand and streamline and optimise the process of acquiring vitamin A premix, enhancing the availability of quality vitamin A premix at competitive prices, primarily for these small and medium-sized oil producers.

\section{NEW COMPLIANCE BEHAVIOUR SCORE FOR PRODUCERS}

Our research developed and tested a theoretically grounded (30) compliance behaviour score that captures the methods, monitoring, and implementation related to the fortification of edible oil. As outlined earlier in the detailed description of our methodology, the score comprises indicators of premix storage, measurement and mixing capacity, fortification practices and documentation, fortification-related quality control, and quality assurance capacity and practices. While the compliance behaviour score requires further testing and validation in Bangladesh and other contexts, it represents an advance in the methods and metrics available to assess compliance, compliance propensity, and compliance-related behaviours. The fortification community has acknowledged the difficulty in measuring compliance and has recommended the implementation of a systems-based approach to determine compliance, which emphasises the process of fortification over regular testing of fortified food samples to quantify micronutrient content (23). This score is a conceptually sound methodological innovation, was confirmed to have high internal validity, and should be implemented and validated in future studies.

\section{ADDRESSING FORTIFICATION AND SAFETY OF BULK OIL}

Our findings underscore the need to ensure traceability across the edible oil value chain. We found that bulk oil was widely available and in high demand from consumers. These findings

\footnotetext{
15 https://www. dhakatribune.com/feature/food/2019/03/28/no-vitamin-a-found-in-17-non-bottled-edible-oil-samples; https://www. dhakatribune.com/bangladesh/2020/04/25/bsti-bans-17-food-products-of-12-companies; https://www. dhakatribune.com/bangladesh/2020/05/11/bsti-bans-43-substandard-products; (Accessed June 29, 2020)
} 
are not unique to Bangladesh. A study in Indonesia estimated that unbranded oil constituted approximately $70 \%$ of the total oil traded in the country at that time (31). A recent study of vitamin A stability in supply chains found that the retailing of edible oil in loose form is also very frequent in Senegal and Benin (32), with over $80 \%$ of the shops sampled found to be selling oil in this form. In India, the sale of bulk oil is common $(33,34)$ and has been attributed to fragmented edible oil markets. Without adequate labelling and traceability, consumers in Bangladesh cannot be assured of quality (nutrient content in line with standards)—or even that they are purchasing soybean oil as opposed to palm oil.

A concern that warrants further study is the potential for food safety risks associated with the sale of bulk oil. Because the drums used to transport bulk oil were observed to be visibly dirty and may contain residue from previous contents such as chemicals and paint, and may be only minimally washed, there are plausible concerns regarding contamination. In Bihar, India, for example, there were case reports of the deaths of schoolchildren that were attributed to organophosphate poisoning due to the cooking oil they were fed having been stored in a container formerly used for insecticides (35). While this poisoning was an extreme occurrence that has not been similarly documented in Bangladesh, it highlights a plausible cause for concern. Clearly further exploration and analysis are warranted.

Ensuring that all edible oil, including bulk oil, can be traced to the producer and is subject to regulatory monitoring is paramount for effective food control and food safety. However, as with many other national programmes, there is limited public industry data or information available, such as verifiable data on production across different types of producers or on procurement of premix by producers. This creates an environment of secrecy within an industry whose products are of strong public interest but which is characterised by a weak sense of accountability between those directly involved in the value chain and those who are supposed to regulate the behaviour of value chain actors. Digital solutions and connected technologies (such as digital dosifiers, blockchain technology, process analytical technologies, the internet of things, and other innovations) coupled with open-source structures that provide such data at transaction points could drive compliance by all actors in the value chain and should be urgently explored (36). In Bangladesh, a web-based management information system for fortification programmes, FortifyMIS (37), is in the early stages of rollout and can perhaps address some of these information gaps between value chain actors, food producers, regulatory monitoring inspectors, and laboratory and central government staff. At a minimum, traceability measures should include mandatory labelling of bulk oil, regulation of quality of packaging (drums), and penalising those who purchase bulk oil if caught with unlabelled or unsafe drums.

\section{LIMITATIONS AND SUGGESTIONS FOR FURTHER RESEARCH}

This study was undertaken in the context of intensified efforts by the government to enforce the law on mandatory fortification and to review requirements for bulk oil sold in drums. As a result of heightened sensitivities, some oil producers were reluctant to be interviewed, creating a potential over-representation of more open and willing producers in our sample. To address this issue, the quantitative survey was designed to enable us to carry out several robustness exercises, while the qualitative information was triangulated with information from other key informants, both within and outside the edible oil value chain. 
One area that holds significant promise to improve fortification outcomes is the use of more data-driven monitoring. This would require verification of information on premix use and production levels, which is currently unavailable. As noted above, digital solutions could clearly offer greater timeliness and could complement and eventually replace face-to-face inspection processes if data availability, reliability, and analytical capacity can be addressed. However, exploring the potential for improved measures in this area was outside the scope of this study, and more work is needed.

Further application and validation of the compliance behaviour score is also recommended. Future studies should assess the accuracy of such measures as a means of predicting compliance. If validated, it offers a more rapid and systems-based means of assessing compliance, which can complement periodic testing.

Finally, the studies were conducted prior to the Covid-19 pandemic, which has resulted in widespread food system disruptions globally and in Bangladesh. For example, there have been reports of decreased sales, difficulty paying staff, difficulty accessing inputs, and decreased production volumes (38). These factors may have affected the value chains studied and presented in this paper. While we are unable to provide detailed evidence on the impacts and implications for the findings and recommendations in this report, Box 1 offers preliminary insights and suggestions for further investigation.

\section{BOX 1: COVID IMPACT ON EDIBLE OIL IN BANGLADESH}

Edible oil industry experts anticipated that a slowdown in economic activity during the Covid-19 lockdown would lead to a fall in edible oil sales, due to a decline in household consumption and closure of restaurants in urban areas. However, these predictions proved to be wrong. According to oil refineries and oil packers with whom we conducted rapid interviews in July 2020, total sales did not fall. Instead, there was an increase in the demand for bulk and bottled oil due to organisations carrying out relief work to support households affected by the crisis and to large purchases of bottled oil by the Trading Corporation of Bangladesh (an agency within the Ministry of Commerce)-totalling almost one quarter of the total market demand-to include in its package of essential food items provided to low-income areas at reduced price during emergency situations. Premix supply did not experience disruption during the lockdown, as shipments were delivered on time to oil refineries and premix agents had enough stock to supply oil packers.

The increase in demand for bottled oil during this time means that more fortification than usual may be taking place. To analyse this further, and to understand its implications on compliance within the value chains studied, an assessment of premix availability, potential supply backlogs, and whether there has been a fall in demand for bulk oil from low-income households would need to be carried out. 


\section{CONCLUSION AND RECOMMENDATIONS}

Based on the study findings, we identify five recommendations, designed to realign incentives for oil producers to support fortification. These recommendations are made with a number of key facts in mind, based on our study and wider work on fortification. First, accountability for edible oil fortification in Bangladesh primarily resides with refineries, with secondary responsibility with packers to purchase fortified oil and top up pre-mix as necessary. Second, consumer awareness of edible oil fortification is low across all strata. Third, the purpose of having a fortification mandate is, in any case, to remove consumer choice. Fourth, it should be recognised that the cost of premix is not trivial when considered as a percentage of profits. Fifth, access to high-quality vitamin A premix is a problem for smaller oil packers. Sixth, penalties (fines but also 'naming and shaming') act as a deterrent for unfortified bottled oil, but the lack of traceability of bulk oil means non-compliance goes unpunished. Seventh, until traceability is established, monitoring and enforcement of bulk oil can only be effective at or immediately after oil leaves the refineries. Eighth, producers subject to a higher-than-average frequency of inspections exhibit a higher level of compliance behaviours.

Our recommendations are as follows:

Our first recommendation supports the current government efforts to ensure that all edible oil, including bulk oil, be traceable to the producer. This measure must be approved in order to ensure mandatory labelling by oil refineries of all bulk oil for human consumption, along with replacing drums with more suitable containers that respect food safety. Once labelling is secured, penalties should be levied on oil packers, retailers, or others who purchase unlabelled/unfortified or unsafe bulk oil, if used for consumption.

Second, we recommend raising the rate of producer inspections to at least quarterly. This is in line with our finding regarding the effectiveness of frequent inspections, as well as the MOlnd's recognition of their importance. Regular inspections serve not only for enforcement but also to secure producer confidence in the regulatory process, to ensure producers become accustomed to requirements, and to reduce the perceived cost of compliance. During inspections and other interactions with producers, emphasis should also be placed on information exchange regarding broader aspects of fortification (e.g., health), to enhance cooperation, reduce information disparities, and strengthen regulatory cultures. Such information exchange is not sufficient on its own, but it does complement enforcement. The quality of these efforts is important, and appropriate resources will be needed. The frequency of inspections, and hence resource requirements, can be reduced over time, once the gains from initial frequent interactions are achieved. The focus can then be turned to spot checks and specific transgressions.

Third, we recommend that fines for non-compliance be reviewed in the upcoming amendment of the fortification law, in order to ensure a sufficient deterrent for underfortification. Penalties for the primary producers of oil, who hold the main accountability for fortification, should be higher. Assuming future traceability of bulk oil is secured, oil packers would also be subject to fines if they do not purchase appropriately fortified and labelled 
bulk oil, although these would be at a lower level than refineries. Alongside fines, the MOlnd should continue to use and to scale up the use of reputational incentives, both negative ('shaming') and positive ('faming').

Fourth, suitable quality premix should be available for oil packers, alongside the capacity and equipment to perform adequate quality control. Central or collective purchasing, storage, and on-sale to oil packers, as well as common testing to optimise premix acquisition and quality control, should be explored with local businesses.

Finally, an additional and efficient means to improve monitoring of producer compliance is the use of more data-driven measures, based on verified information provided by producers regarding premix use and production levels. Data that is currently being submitted by producers need to be reconciled, to assess whether the amount of premix used correlates to the amount of fortified food reported as being produced over a certain time period. In the future, digital solutions may help in this respect, although further exploration, development, and testing are needed.

Currently, fortified and non-fortified products co-exist in the Bangladeshi edible oil market, disincentivizing value chain actors to supply fortified products. A systems-based approach is needed to address the governance environment and value chain constraints and incentives, identified as key to ensuring delivery of affordable oil products containing the mandated levels of nutrients that can plausibly affect nutritional outcomes. While the findings and recommendations in this report are specific to the experiences with fortified edible oil in Bangladesh, the problem of sub-optimal fortification implementation and delivery of fortified staple foods is widespread. The analytical approach and learning set out in this report, particularly the focus on understanding industry behaviour, have relevance for other contexts, even if specific recommendations to improve outcomes are likely to vary. 


\section{REFERENCES}

1. Horton S. The Economics of Food Fortification. J Nutr. 2006;136:1068-71.

2. Walters D, Ndau E, Saleh N, Mosha T, Horton S. Cost-effectiveness of sunflower oil fortification with vitamin A in Tanzania by scale. Matern Child Nutr. 2019;15(S3):e12720.

3. Keats EC, Neufeld LM, Garrett GS, Mbuya MN, Bhutta ZA. Improved micronutrient status and health outcomes in low- and middle-income countries following large-scale fortification: evidence from a systematic review and meta-analysis. Am J Clin Nutr. 2019;00:1-13.

4. Aaron GJ, Friesen VM, Jungjohann S, Garrett GS, Neufeld LM, Myatt M. Coverage of Large-Scale Food Fortification of Edible Oil, Wheat Flour, and Maize Flour Varies Greatly by Vehicle and Country but Is Consistently Lower among the Most Vulnerable: Results from Coverage Surveys in 8 Countries. J Nutr. 2017;147:984S-994S.

5. International Centre for Diarrheal Diseases and Research, Bangladesh (ICDDR,B); United Nations Children's Fund (UNICEF). National micronutrients status survey 2011-12. Dhaka: ICDDR,B and UNICEF; 2013.

6. Raghavan R, Aaron GJ, Nahar B, Knowles J, Neufeld LM, Rahman S, et al. Household coverage of vitamin A fortification of edible oil in Bangladesh. PLoS ONE; 2019;14:e0212257.

7. People's Republic of Bangladesh. Vitamin A Enrichment in Edible Oil Act, 2013, Act No. 65 (Nov 27, 2013).

8. Kar BK. National Program Case Studies and Lessons Learned From Bangladesh. In: Mannar MGV, Hurrell RF, editors. Food Fortification in a Globalized World. Academic Press; 2018. p. 349-53.

9. People's Republic of Bangladesh. The Fortification of Edible Oil with Vitamin 'A' Rules, 2015.

10. Mkambula P, Mbuya MNN, Rowe LA, Sablah M, Friesen VM, Chadha M, et al. The Unfinished Agenda for Food Fortification in Low- and Middle-Income Countries: Quantifying Progress, Gaps and Potential Opportunities. Nutrients; 2020;12:354.

11. Global Alliance for Improved Nutrition (GAIN); International Centre for Diarrheal Diseases and Research, Bangladesh (icddr,b). Assessment of presence of edible oil brands in Bangladesh and their vitamin A content. Geneva, Switzerland: GAIN; 2017.

12. Jungjohann S, Ara G, Pedro C, Khanam M, Friesen V, Ahmed T, et al. Fortification Quality Is High for Packaged and Branded Edible Oil but Low for Oil Sold in Unbranded, Loose Form: Findings from a Market Assessment in Bangladesh (P24-047-19). Curr Dev Nutr. 2019;3(Supplement_1):nzz044.P24-047-19.

13. Aung MM, Chang YS. Traceability in a food supply chain: Safety and quality perspectives. Food Control. 2014;39:172-84. 
14. Luthringer CL, Rowe LA, Vossenaar M, Garrett GS. Regulatory Monitoring of Fortified Foods: Identifying Barriers and Good Practices. Glob Health Sci Pract. 2015;3:446-61.

15. Rowe LA, Luthringer CL, Garrett GS. Regulatory Monitoring of Mandatory Fortification Programs. In: Mannar MGV, Hurrell RF, editors. Food Fortification in a Globalized World. Academic Press; 2018. p. 283-90.

16. Averch H, Johnson LL. Behavior of the Firm Under Regulatory Constraint. Am Econ Rev. 1962;52:1052-69.

17. Myers SC. A Simple Model of Firm Behavior under Regulation and Uncertainty. Bell J Econ Manag Sci. 1973;304-15.

18. Shaffer B. Firm-level Responses to Government Regulation: Theoretical and Research Approaches. J Manag. 1995;21:495-514.

19. Oxford Policy Management, Innovision, Institute of Development Studies, Global Alliance for Improved Nutrition. Value Chain Analysis of Edible Oil. Study A of the project "Compliance of Edible Oil and Salt Fortification with National Program Standards in Bangladesh: Implementation Research to Inform Quality Improvement Efforts". Geneva, Switzerland: Global Alliance for Improved Nutrition; 2020.

20. Institute of Development Studies, Innovision, Oxford Policy Management, Global Alliance for Improved Nutrition. Understanding Drivers of Behaviour in Value Chains. Study B of the project "Compliance of Edible Oil and Salt Fortification with National Program Standards in Bangladesh: Implementation Research to Inform Quality Improvement Efforts". Geneva, Switzerland: Global Alliance for Improved Nutrition; 2020.

21. Institute of Development Studies, Innovision, Oxford Policy Management, Global Alliance for Improved Nutrition. Drivers of Compliance with Food Fortification Regulations among Producers of Edible Oil and Salt in Bangladesh. Study C of the project "Compliance of Edible Oil and Salt Fortification with National Program Standards in Bangladesh: Implementation Research to Inform Quality Improvement Efforts". Geneva, Switzerland: Global Alliance for Improved Nutrition; 2020.

22. Global Alliance for Improved Nutrition (GAIN) and Project Healthy Children (PHC). Regulatory monitoring of national food fortification programs: A policy guidance document. Global Fortification Technical Advisory Group (GF-TAG); 2018.

23. Hosen G, Ferdous S. The Role of Mobile Courts in the Enforcement of Laws in Bangladesh. North Univ J Law. 2014;1:82-95

24. BSTI warns refiners of violating vitamin fortification requirement. The Financial Express 2017 Nov 29.

25. Andersen ES, Philipsen K. The evolution of credence goods in customer markets: exchanging "pigs in pokes". Paper presented at the DRUID Winter Seminar; 1998 Jan 810; Middelfart, Denmark. 
26. Erdem T, Swait J, Louviere J. The impact of brand credibility on consumer price sensitivity. Int J Res Mark. 2002;19:1-19.

27. Diosady LL, Krishnaswamy K. Micronutrient Fortification of Edible Oils. In: Mannar MGV, Hurrell RF, editors. Food Fortification in a Globalized World. Academic Press; 2018. p. 167-74.

28. Anneberg I, Vaarst M, Sandøe P. To inspect, to motivate —or to do both? A dilemma for on-farm inspection of animal welfare. Anim Welf. 2013;22:185-94.

29. McCaffrey DP, Smith AE, Martinez-Moyano IJ. Then Let's Have a Dialogue: Interdependence and Negotiation in a Cohesive Regulatory System. J Public Adm Res Theory. 2006;17:307-334.

30. Henson S, Heasman M. Food safety regulation and the firm: understanding the compliance process. Food Policy. 1998;23:9-23.

31. Soekirman, Soekarjo D, Martianto D, Laillou A, Moench-Pfanner R. Fortification of Indonesian Unbranded Vegetable Oil: Public-Private Initiative, from Pilot to Large Scale. Food Nutr Bull. 2012;33(4_suppl3):S301-9.

32. Hemery, Y. Stability of vitamin A in fortified oils in real life supply chain conditions: StaVitA. Final Report. Institute of Research for Development, Nutripass; 2020. Sponsored by Global Alliance for Improved Nutrition (GAIN).

33. Narayana VL, Babu MSD. Edible Oil Marketing in Tamil Nadu. J Contemp Res Manag. 2009; Jan-Mar.

34. Shiva Kumar MP. Brand preference and buying decision: A study with reference to organized Indian edible oil brands. Afr J Mark Manag. 2014;6:17-26.

35. Idrovo AJ. Food poisoned with pesticide in Bihar, India: new disaster, same story. Occup Environ Med. 2014;71:228.

36. World Food Programme Accelerator team. Food Fortification Quality Workshop with the Bill \& Melinda Gates Foundation and the WFP Innovation Accelerator; 2019 Apr 24-25; Munich, Germany.

37. Garcia-Casal MN, Mowson R, Rogers L, Grajeda R. Risk of excessive intake of vitamins and minerals delivered through public health interventions: objectives, results, conclusions of the meeting, and the way forward. Ann N Y Acad Sci. 2019;1446:5-20.

38. Global Alliance for Improved Nutrition (GAIN). Impact of COVID-19 on Food Systems: A Situation Report. Edition 3; 2020, May 13. 